\title{
CURARE SENSITIVITY IN OCULAR MYOPATHY
}

\author{
J. C. JACOB, F.R.C.P.(C), AND GEORGE P. VARKEX, F.R.C.P.(c) ${ }^{\circ}$
}

OCULAR MYOPATHY is a relatively uncommon type of muscular dystrophy. The clinical entity has been described under various titles, some of which are: progressive dystrophy of the external ocular muscles, ${ }^{2}$ chronic external ophthalmoplegia, $^{2}$ descending ocular myopathy, ${ }^{3}$ oculopharyngeal muscular dystrophy. ${ }^{4}$

The usual clinical features are ptosis, a variable degree of restriction of extraocular movements involving one or both eyes (which may be asymmetrical), together with a varying degree of weakness of trunk and limb muscles. There are no periods of exacerbation and remission, nor is the ophthalmoplegia and muscle weakness improved on administration of anticholinesterase drugs. There is usually a very gradual progression of muscle weakness. In some cases, there is a total, bilateral, external ophthalmoplegia, with or without dysphagia and weakness of limb muscles. When familial, the mode of inheritance is uncertain." Seven patients with ocular myopathy have been studied, the clinical features having been elaborated in a previous report. ${ }^{6}$ Four of these patients were given a curare test, as described below, and exhibited an unusual sensitivity to the drug. This response is reported here.

The curare test was administered in every instance, with appropriate precautions being observed in cases of respiratory failure. An intravenous dose of $0.05-$ $0.1 \mathrm{mg}$. d-tubocurarine per stone body weight ${ }^{7}$ was taken as the concentration which does not affect neuro-muscular conduction, and therefore muscle strength, in a normal individual. The solution used contained $1 \mathrm{mg}$. d-tubocurarine per c.c., 0.1 c.c. being administered intravenously every thirty seconds.

\section{CASE I}

P.R., a sixteen-year-old girl was seen for the complaint of menstrual irregularity and vague generalized weakness. The menstrual disorder was found to be due to an infantile uterus. The striking feature on clinical examination was bilateral ptosis, together with an almost total bilateral symmetrical, external ophthalmoplegia which the patient stated had remained unchanged since her childhood and which did not interfere with her usual activities. No objective evidence of decreased limb or trunk muscle power was obtained. An intravenous injection of $10 \mathrm{mg}$. of edrophonium chloride (Tensilon ${ }^{\otimes}$ ), did not alter the ophthalmoplegia, though one observer thought that the ptosis was temporarily enhanced.

A curare test was undertaken as described above. The patient weighed 110 pounds. After $0.5 \mathrm{mg}$. curare had been given, the patient noted worsening of the ptosis, difficulty in swallowing, "heaviness" of limbs, inability to flex her neck, which rapidly progressed to a flaccid paralysis of all limbs and a cessation of respiration. India.

Departments of Neurology and Anesthesiology, Christian Medical College Hospital, Vellore, 
Artificial respiration was commenced immediately and 1/100 gr. atrophine and $1.5 \mathrm{mg}$. prostigmine given intravenously. This did not alter the profound muscle weakness; it was not until 15 minutes later that respiratory movements of the chest recommenced and artificial respiration could be discontinued. The limb and trunk weakness persisted for 24 hours, when limbs could be moved against gravity; however, it was four hours after curare administration that limb power returned to normal.

\section{Case II}

J.P., a 23-year-old male, brother of Case I, was referred for neurological assessment, as ptosis had been noted on a routine pre-employment medical examination. The patient was asymptomatic; he stated that ptosis and inability to move the eyeballs had been present "since childhood," and had not interfered with normal activity. On examination there was found to be a total bilateral symmetrical, external ophthalmoplegia. Though he had poor muscle bulk, no weakness could be detected in trunk or limbs. Ten mg. of edrophonium chloride produced no change in the external ophthalmoplegia.

A curare test was undertaken as described above. The patient weighed 86 pounds. Respiratory function, assessed with a Wright's respirometer before administration of curare, showed a tidal volume of 300 c.c., and a forced expiratory volume of 1.5 litres. Within 15 seconds of administration of $0.5 \mathrm{mg}$. curare, there was enhancement of ptosis, difficulty in swallowing, inability to flex the neck, and marked weakness of limb muscles. Respirations appeared laboured at this time. The tidal volume was now 100 c.c., while the forced expiratory volume had decreased to 0.75 litres. Intravenous atropine 1/100 gr. and prostigmine 1.5 mg. did not alter the muscle weakness, which persisted for twenty-five minutes before gradually returning to normal.

The other two cases showed a lesser degree of sensitivity to curare.

\section{Case III}

K.G., a 30-year-old woman, was seen for a vague symptom of "visual difficulty" which had been noted for two years. Abnormal findings on clinical examination included bilateral ptosis which was more marked on the right, as well as a restriction of movements in superior, lateral, and medial directions. Intravenous injection of $10 \mathrm{mg}$. of edrophonium did not alter the ophthalmoplegia.

A curare test was undertaken as described above. The patient weighed 110 pounds. Twenty seconds after administration of $0.5 \mathrm{mg}$. curare, there was enhancement of ptosis, together with further accentuation of the ophthalmoplegia bilaterally. No pharyngeal or limb muscle weakness was detected. Intravenous atropine gr. 1/100 and $1.5 \mathrm{mg}$. prostigmine did not induce any change. The enhanced ophthalmoplegia returned to preinjection levels ten minutes after the curare had been administered.

\section{Case IV}

K.N. was seen in 1958 for the complaint of drooping of the eyelids. Examination at that time revealed an almost total bilateral symmetrical, external ophthalmo- 
plegia. When he was seen again in 1964 the ophthalmoplegia was unchanged; he had in addition weakness at the shoulder and pelvic girdles and some weakness of the small muscle of the hands. The muscle weakness did not cause functional disability, so that he could continue in his occupation as a tailor.

Ten mg. of edrophonium administered intravenously produced no change in the ophthalmoplegia or limb girdle weakness. A curare test was performed in the manner described above. The patient weighed 138 pounds. After $1 \mathrm{mg}$. curare was given, there was an enhancement of the ptosis, which was not improved with intravenous atropine and prostigmine. The enhanced ptosis returned to normal (pre-test level) 10 minutes after the injection.

\section{Discussion}

These cases of ocular myopathy are differentiated clinically from myasthenia gravis, though an unusual sensitivity to curare is a feature common to both conditions. We do not consider these cases to represent "myasthenic myopathy," as has been suggested by Rowland and Eskenazi. ${ }^{8}$

Pelikan et al., in a study determining the threshold dose for effect on the near point of convergence in an equal number of myasthenic and normals, showed that 3-4 per cent of the normals might be as sensitive to curare as myasthenics. They also found that $3-4$ per cent of patients with myasthenia might not be more sensitive than normal individuals. The significance of these observations, particularly the former, in clinical diagnostic problems is not discussed.

Other neuromuscular disorders (besides myasthenia gravis) which share this feature of an unusual sensitivity to curare include malnutrition, ${ }^{10}$ some cases of amyotrophic lateral sclerosis, ${ }^{11}$ and the myasthenic syndrome occasionally associated with systemic malignancy, notably with small cell bronchogenic carcinoma. ${ }^{12}$ The nature of the neuromuscular block induced by curare in these patients with ocular myopathy is not clear. In the normal situation, curare induced a nondepolarizing or a "competitive" block at the neuromuscular junction, which is readily reversed by neostigmine. That this does not occur in these cases is clear from the test responses. Ross ${ }^{13}$ has described a similar group of cases showing an unusual sensitivity to curare. Electromyographic studies in his cases, including repetitive peripheral nerve stimulation and recording of action potentials, did not show either the myasthenic type of response, nor that seen in patients with the myasthenic syndrome associated with malignancy.

It is clear that there is no uniformity in the degree of sensitivity to curare as shown by these patients. Rowland et al. ${ }^{14}$ described a probable case of ocular myopathy with no enhancement of weakness after curare. Further clinical, electrical, and biochemical studies are in progress to attempt to elucidate further the nature of this unusual sensitivity to curare.

Anesthetists are aware of succinylcholine-induced apnoea caused by prolonged neuromuscular block in patients with abnormal serum pseudochalinesterase. ${ }^{15}$ Attention is drawn in this paper to an unusual type of myopathy, namely ocular myopathy, where administration of curare may also lead to prolonged block in neuromuscular transmission, the pathogenesis of which is yet to be clarified. 


\section{SUMMARY}

1. The clinical features of ocular myopathy are briefly described.

2. The observations made during administration of very small doses of curare in 4 cases of ocular myopathy are recorded. Attention is drawn to the unusual sensitivity to curare, which is not reversed by neostigmine in these cases of ocular myopathy.

3. The significance of these observations is discussed, and other neuromuscular disorders showing a similar sensitivity to curare are indicated.

\section{RÉsuMÉ}

La myopathie oculaire est un type rare de dystrophie musculaire; elle est caractérisée par une ophtalmoplégie externe et de la faiblesse des membres, sans exacerbation ni rémission, et sans amélioration après administration d'anticholinesterase. Nous avons fait l'épreuve à la tubocurarine chez quatre porteurs de cette sorte de myopathie inusuelle à ce médicament et on ne pouvait le renverser avec de la néostignine. Le degré de sensibilité n'est pas uniforme, mais il est étonnant. Les autres désordres neuromusculaires (la myasthénie grave incluse) chez qui l'on observe une sensibilité inhabituelle au curare sont: certains cas de sclérose latérale amyotrophique et le syndrome myasthénique relié au carcinome endobronchique.

La nature du blocage neuromusculaire inhabituel observé chez ces malades avec le curare exige de plus amples recherches.

\section{REFERENCES}

1. Knон, L. G. \& Nevn, S. Progressive Dystrophy of the External Ocular Muscles. Brain. 74: 115 (1951).

2. Scrwarz, G. A. \& Lru, C. Chronic Progressive external ophthalmoplegia. A.M.A. Arch. Neurol. \& Psychiat. 71: 31 (1954).

3. LeEs, F. \& LIVERSEDGE, L. A. Descending Ocular Myopathy. Brain. 85: 701 (1962).

4. Victor, M.; Hayes, R.; \& Adams, R. D. Oculopharyngeal Muscular Dystrophy. New England J. Med. 267: 1267 (1962).

5. Adams, R. D.; Denny-Brown, D.; \& Pearson, C. M. Diseases of Muscles, A Study in Pathology. 2nd ed., New York: Hoeber Medical Div. of Harper and Bros (1962).

6. JACOB, J. C. \& CrandY, J. Ocular Myopathy. Neurology (India), in press (1966).

7. GrAy, T. C. The Clinical Applications of Relaxant Drugs in General Anaesthesia. Ed. F. T. Evans and T. C. Gray. London: Butterworths (1965).

8. Rowland, L. P. \& EsKenazi, A. N. Myasthenia Gravis with Features Resembling Muscular Dystrophy. Neurology. 6: 667 (1956).

9. Peuman, E. W.; TeTher, J. E.; \& UnNa, K. R. Sensitivity of Myasthenia Gravis Patients to Tubocurarine and Decamethonium. Neurology. 3: 284 (1953).

10. Dennx-Brown, $D$. Neurological Conditions Resulting from Prolonged and Severe Dietary Restriction. Medicine. 26: 41 (1947).

11. Mulder, D. W.; Lambirrt, E. H.; \& Eaton, L. M. Myasthenic Syndrome in Patients with Amyotrophic Lateral Sclerosis. Neurology. 9: 627 (1959).

12. Rooke, E. D.; Mulder, D. W.; Eaton, L. M.; \& Lambert, E. H. Studies of Neuromuscular Conduction in Myasthenia Gravis and Related Disorders. Proc. 2nd Internat. Symposium on Myasthenia Gravis. Springfield, Illinois: C. C. Thomas (1961).

13. Ross, R. T. Ocular Myopathy Sensitive to Curare. Brain. 86: 67 (1963).

14. RowLAND, L. P.; ARaNow, H.; \& Hompzr, P. F. A. Observations on the Curare Test in the Differential Diagnosis of Myasthenia Gravis. Proc. 2nd Internat. Symposium on Myasthenia Gravis. Springfield, Mlinois: C. C. Thomas (1961).

15. Busr, G. H. Prolonged Apnoea due to Suxamethonium. Brit. J. Anaesth. 33: 454 (1961). 